\title{
Selenium-related nutritional status in patients with common variable immunodeficiency: association with oxidative stress and atherosclerosis risk
}

Itana Gomes Alves Andrade ${ }^{*}$, Fabíola Isabel Suano de Souza', Fernando Luiz Affonso Fonseca², Carolina Sanchez Aranda ${ }^{1}$ and Roseli Oselka Saccardo Sarni ${ }^{3,4}$

\begin{abstract}
Background: Common variable immunodeficiency (CVID) is an inborn errors of immunity, that leads to recurrent chronic infections and autoimmune/ inflammatory diseases and neoplasms. It is considered that these condition is related to persistent this immune-inflammatory stimulation and increased oxidative stress. A positive impact on the survival of patients with an inborn error of immunity was observed with advanced clinical care protocols, thus raising concerns about the risk of developing other associated chronic diseases, such as atherosclerosis. Studies suggest that selenium (Se) is a protective trace element against damage caused by oxidative stress. Thus, it is postulated that adequate consumption reduces the risk of some chronic diseases.

Results: Se median levels (ug/L) [45.6 (37.3-56.2) vs. 57.8 (46.0-66.0); $p=0.004]$ and GPX activity (U/L) [7682 (6548$8446)$ vs. $9284(8440-10,720) ; p=0,002$ ) were significantly lower in patients compared to controls. Inadequacy of Se levels was observed in $50 \%$ of the patients. There was a higher percentage of high values of C-reactive protein in the group of CVID patients compared to controls [8 (36.4\%) vs. 2 (11.1\%); $p=0.082$ ]. Higher concentrations of oxidized LDL (45.3 mg/dL vs. $33.3 \mathrm{mg} / \mathrm{dL} ; p=0.016)$ and lower concentrations of Apo A-1 (98.5 mg/dL) vs. $117.0 \mathrm{mg} /$ $\mathrm{dL} ; p=0.008$ ) were observed in the CVID group compared to the control. There was a significant and positive correlation between Se plasma levels and apolipoprotein A-1 concentrations in CVID group (rho = 0.577; $p=0.001$ ). Se values less than $46 \mu \mathrm{g} / \mathrm{L}(\mathrm{OR}=3.590 ; 95 \% \mathrm{Cl} 1.103$ to $11.687 ; p=0.034)$ and $\mathrm{GPX}$ activity below the 4th quartile $(\mathrm{OR}=21.703 ; 95 \% \mathrm{Cl} 2.534$ to $185.914 ; p=0.005)$ were independently associated, after adjustment for age, overweight and dyslipidemia, with the CVID group (Table 5).

Conclusion: This study showed an higher percentage of high us-CRP, lower values of plasma Se and GPX activity, higher concentrations of LDLox and lower levels of Apo A-1 in CVID patients in comparison to controls, suggesting oxidative stress and cardiovascular risk.These data point to the importance of assessing the Se status and cardiovascular risk in these patients.
\end{abstract}

Keywords: Common variable immunodeficiency, Dyslipidemia, Oxidative stress, Cardiovascular risk, Selenium

\footnotetext{
* Correspondence: itanaandrade@yahoo.com.br

'Department of Pediatrics, Universidade Federal de São Paulo - Escola

Paulista de Medicina, Rua Dr. Diogo de Faria, 671, São Paulo, SP CEP 04037002, Brazil

Full list of author information is available at the end of the article
}

(C) The Author(s). 2021 Open Access This article is licensed under a Creative Commons Attribution 4.0 International License, which permits use, sharing, adaptation, distribution and reproduction in any medium or format, as long as you give appropriate credit to the original author(s) and the source, provide a link to the Creative Commons licence, and indicate if changes were made. The images or other third party material in this article are included in the article's Creative Commons licence, unless indicated otherwise in a credit line to the material. If material is not included in the article's Creative Commons licence and your intended use is not permitted by statutory regulation or exceeds the permitted use, you will need to obtain permission directly from the copyright holder. To view a copy of this licence, visit http://creativecommons.org/licenses/by/4.0/ The Creative Commons Public Domain Dedication waiver (http://creativecommons.org/publicdomain/zero/1.0/) applies to the data made available in this article, unless otherwise stated in a credit line to the data. 


\section{Introduction}

Selenium (Se) is an essential micronutrient for antioxidant defense that integrates an important part of selenoproteins. The protection provided by $\mathrm{Se}$ against dyslipidemia and cardiovascular diseases (CVD) is supported by its role in the antioxidant defense mediated by the glutathione peroxidase (GPX) family. In this context, GPX reduces the formation of hydroperoxides of phospholipids and cholesterol esters, and prevents oxidized low-density lipoprotein (LDL) artery sedimentation and, consequently, slows or prevents the atherosclerotic process [1-3].

The inadequate consumption of Se and the presence of polymorphism in the GPX1 gene are related to the lower activity of this enzyme, which can harm the body's antioxidant defense system [4]. Some studies have highlighted the relationship between single nucleotide polymorphism (SNP) in GPX genes with increased risk of CVD and metabolic syndrome [5, 6]. The cardioprotective effect of Se is still controversial probably due to the limited trial evidence that is available to date [7].

Common Variable Immunodeficiency (CVID) is a syndrome encompassing a heterogeneous group of diseases characterized by changes in the immune function involving $\mathrm{T}$ and $\mathrm{B}$ cells, and inadequate production of antibodies, causing recurrent bacterial infections [8]. Because CVID patients may have recurrent or chronic infections and autoimmune/inflammatory diseases and neoplasms, it was suggested that these conditions led to persistent immune stimulation and increased oxidative stress [9]. In a recent study, the analysis of oxidative stress markers in the CVID patients suggested a series of abnormalities in the anti-oxidant system [10].

In this context, Vieira et al. (2015) [11] found increased inflammatory markers and lower high-density lipoprotein cholesterol (HDL-c) and Apoliprotein A-1 (apo A-1) concentrations, suggesting a predisposition to cardiovascular risk in these patients.

A positive impact on the survival of patients with an inborn error of immunity (IEI) was observed with advanced clinical care protocols, thus raising concerns about the risk of developing other associated chronic diseases, such as atherosclerosis.

This study aims to describe the plasma levels of Se and erythrocyte glutathione peroxidase activity in CVID patients and to relate them to lipid status biomarkers.

\section{Methods}

This is a cross-sectional controlled study evaluating 32 patients of both genders aged from 9 to 61 years, diagnosed with common variable immunodeficiency, according to the criteria of the European Immunodeficiency
Society, conducted from 2016 to 2019 [12]. The patients were being followed up at the Discipline of Allergy and Clinical Immunology of Federal University of São Paulo, Brazil.

The control group was composed of 37 healthy volunteers matched by age and gender.

Exclusion criteria for patients and controls were considered: presence of acute infection, and use of corticosteroids at the time and in the 3 months preceding the collection of laboratory tests.

The study was approved by the Research Ethics Committee of Federal University of São Paulo (No. 972812/ 2015), and financed by the São Paulo Research Foundation - FAPESP $n^{\circ}$ 2015/13308-9. All methods were carried out in accordance with relevant guidelines and regulations including Declaration of Helsinki.

The demographic, clinical, and treatment data were obtained from the patients' charts. The family history risk of atherosclerosis was assessed for patients and controls.

\section{Anthropometric and food intake assessment}

The anthropometric assessment included measurements of weight, height, and waist circumference. Weight and height were measured according to World Health Organization (WHO) [13].

The body mass index-for-age (BMI/A) and height-forage $(\mathrm{H} / \mathrm{A})$ indicators were calculated for the classification of nutritional status, expressed as Z-score, using De Onis (2007) [14] as a reference, for children and adolescents, and the body mass index (BMI), as proposed by the World Health Organization, for adults (WHO, 1995). The classification by Freedman et al. [15] was used to assess the waist circumference of children and adolescents, and values above the 90th percentile were considered high. Adults were classified according to the WHO [13].

Food intake was assessed with the 24-h dietary recall [16], applied in three times [17], with a 15-day interval. The calculation of energy and nutrients intake was perfomed using the software DietwinR, comparing patients and controls.

Considering that food composition tables available in some software do not have complete data on Se content in foods, these data were included manually based on the article by Ferreira et al. (2002) [18].

\section{Biochemical assessment}

After a 12-h fast, blood was collected to analyze plasma Se, erythrocyte glutathione peroxidase activity, lipid profile, apolipoproteins A-1 and B, oxidized LDL (LDLox), malondialdehyde (MDA), ultra-sensitive Creactive protein (us-CRP), adiponectin, insulin, glucose, aspartate aminotransferase (AST), alanine 
transaminase (ALT) and gamma-glutamyl transpeptidase (Gamma GT).

All analyzes were performed using standard methods and good practice in clinical analysis. Plasma Se levels were obtained by atomic absorption spectrophotometry by graphite oven, with a detection limit of $1.0 \mathrm{mcg} / \mathrm{L}$ and linearity of $400.0 \mu \mathrm{g} / \mathrm{L}$. The coefficient of variance was $0.8 \%$. For classification purposes, a cut-off point < $46 \mu \mathrm{g} / \mathrm{L}$ was adopted for inadequacy. Erythrocyte glutathione peroxidase (GPX) activity was measured by the method based on that Paglia and Valentine (RANDOX). The method is linear up to a concentration of $925 \mathrm{U} / \mathrm{L}$. The sensitivity was $75 \mathrm{U} / \mathrm{L}$ and the coefficient of variance was $3.4 \%$. GPX activity values lower than $4171 \mathrm{U} / \mathrm{L}$ were considered inadequate.

The lipid peroxidation was determined by the TBARS method (thiobarbituric acid-reactive substances) which is based on the reaction of malondialdehyde (MDA), a compound formed by the oxidation of lipids, with thiobarbituric acid (TBA) and is given in MDA equivalents, according to Satoh [19]. Us-CRP was determined using the turbidimetric-immunological method (Roche). The measurement range is $1.0-200 \mathrm{mg} / \mathrm{L}$ ). Adiponectin levels were measured by ELISA.

The lipid profile, including triglyceride (TG), total cholesterol (TC), and high-density lipoprotein cholesterol (HDL-c) was measured by enzymatic-colorimetric method. LDL-c and VLDL-c were calculated using the formula by Friedewald et al. (1972) [20]. For classification, the cut-off points suggested by the American Academy of Pediatrics [21] and the National Cholesterol Education Program (NCEP) [22] were adopted. The presence of dyslipidemia was considered when the TC > $170 \mathrm{mg} / \mathrm{dL}$ for children/adolescents and $>200 \mathrm{mg} / \mathrm{dL}$ for adults, or LDL-c $>110 \mathrm{mg} / \mathrm{dL}$ for children/adolescents and $>129 \mathrm{mg} / \mathrm{dL}$ for adults, or triglycerides $>100 \mathrm{mg} / \mathrm{dL}$ for children/adolescents and $>150 \mathrm{mg} / \mathrm{dL}$ for adults and/ or HDL-c $<35 \mathrm{mg} / \mathrm{dL}$ for children/adolescents, $<40 \mathrm{mg}$ / $\mathrm{dL}$ for women and $<50 \mathrm{mg} / \mathrm{dL}$ for men.

The non-HDL-c cholesterol (NHDL-c) were obtained by subtracting the HDL-c values from the TC values and classified according to the Bogalusa [23] and NCEP. The following atherogenic indices were also calculated: total cholesterol/HDL-c, LDL-c/HDL-c, Apo B/Apo A-1, LDL-c/Apo B, and HDL-c/Apo A-1.

Apo A-1 and Apo B were measured using kits of turbidimetric methods for human Apo A-1 and Apo B (Roche, Indianapolis, IN, USA) and oxidized LDL (LDL ox) by ELISA (Wuhan Fine Biological Technology, Wuhan, China).

Glycemia was measured by enzymatic reference method with hexokinase, while insulin was quantified by electrochemiluminescence. The fasting blood glucose and insulin values were used to calculate the HOMA-IR
(Homeostasis Model Assessment of Insulin Resistance) using the following formula: HOMA-IR = fasting glucose $(\mathrm{mmol} / \mathrm{l}) \times$ fasting insulinemia $(\mu \mathrm{U} / \mathrm{ml}) / 22.5$.

Alanine transaminase (ALT), aspartate aminotransferase and the gamma-glutamyl transpeptidase were measured by enzymatic colorimetric method.

To evaluate cardiovascular risk we considered inflammatory, oxidative stress and lipid status biomarkers.

\section{Statistical analysis}

The SPSS $25.0\left(\mathrm{IBM}^{\circ}\right)$ program was used for statistical analysis. Categorical variables were shown as absolute numbers and percentages, compared using the Chisquare test. The continuous variables were evidenced in the median and interquartile range and compared using the Mann-Whitney test. The Spearman test was used to assess the correlation between continuous variables and glutathione peroxidase and Se levels. Logistic binary regression (enter method) was used to evaluate the variables predicting Se levels $(<46 \mu \mathrm{g} / \mathrm{L})$ and glutathione peroxidase activity $(<1$ st quartile $-<7384.5 \mathrm{U} / \mathrm{L})$. The model included variables that were clinically relevant CVID group, overweight, dyslipidemia and age. Significance level adopted in all analyzes was $5 \%$.

\section{Results}

The classification of the nutritional status of CVID patients and the control group is summarized in Table 1. There was no difference between the groups regarding gender, age, pubertal stage, family cardiovascular risk, and BMI. The presence of dyslipidemia was found in 24/ $32(75.0 \%)$ of the patients.

\section{Demographic, anthropometric and clinical data}

The characterization of CVID patients is established in Table 2. The median age was 36.8 years (min-max 9.661.4 years); there was one child, four teenagers, and the remaining were adults. The delay since onset of symptons and diagnosis was 5 years and 6 months (min-max $0.5-16.4$ years). Of the 32 patients, fourteen (43.8\%) had

Table 1 Demographic and anthropometric data of CVID patients and the control group

\begin{tabular}{llll}
\hline Variables & $\begin{array}{l}\text { CVID Patients } \\
(\boldsymbol{n}=\mathbf{3 2})\end{array}$ & $\begin{array}{l}\text { Control group } \\
(\boldsymbol{n}=\mathbf{3 7})\end{array}$ & $\mathbf{p}$ \\
\hline $\begin{array}{l}\text { Age, median }\left(\mid \mathrm{Q}_{25-75}\right) \\
\text { Gender }\end{array}$ & $36.8(27.9-45.2)$ & $34.7(20.7-44.3)$ & $0.481^{\mathrm{b}}$ \\
$\quad$ Male \% & $14(43.8)$ & $16(43.2)$ & $0.972^{\mathrm{a}}$ \\
BMl, classification, kg/m² & & & \\
Underweight, \% & $2(6.2)$ & $1(2.8)$ & $0.704^{\mathrm{a}}$ \\
Normal, \% & $15(46.9)$ & $18(48.6)$ & \\
Overweight, \% & $15(46.9)$ & $18(48.6)$ &
\end{tabular}

${ }^{\mathrm{a}}$ Chi-square and ${ }^{\mathrm{b}}$ Mann-Whitney test 
Table 2 Classification of age, waist circumference and laboratorial variables in CVID patients

\begin{tabular}{lll}
\hline Variables $(\boldsymbol{n}=\mathbf{3 2})$ & N (\%) \\
\hline Age & 9-19years & $5(15.6)$ \\
& 20-61 years & $27(84.4)$ \\
Waist & Adequate & $20(62.5)$ \\
circumference & High & $12(37.5)$ \\
Lipid profile & High total cholesterol & $7(21.9)$ \\
& High LDL-c & $6(18.8)$ \\
& High triglycerides & $4(12.5)$ \\
& Low HDL-c & $18(56.3)$ \\
Se levels & High NHDL-c & $12(37.5)$ \\
GPX activity & Adequate (> 46 $\mu$ g/L) & $16(50.0)$ \\
\hline N (\%) & Adequate (> 4171 U/L) & $31(96.8)$ \\
LDL-c Low-density lipoprotein, & HDL-c High-density lipoprotein, NHDL-c Non- \\
HDL cholesterol, GPX Erytrhocyte glutathione peroxidase activity &
\end{tabular}

a chronic pulmonary disease (CPD) and were on continuous use of antibiotics, while 5/32 (15.6\%) had chronic diarrhea. All patients received regular immunoglobulin infusion, and only 7/32 (21.9\%) used vitamin or food supplements regularly (data not shown).

\section{Laboratory variables and food intake assessment}

Dyslipidemia was observed in the CVID vs. control group, respectively, in $24(75.0 \%)$ vs. 21 (77.8\%); $p=$ 0.525 . Se levels inadequacy was observed in the CVID vs. control group in $16(50.0 \%)$ vs. $6(22.2 \%) ; p=0.036$, whereas there was no statistically significant difference between groups for the inadequacy of GPX activity lower values1 $(3.1 \%)$ vs. $0(0.0 \%) ; p=0.603$.

Table 3 Comparison of biochemical variables between CVID patients and control group

\begin{tabular}{llll}
\hline Variables & $\begin{array}{l}\text { CVID Patients } \\
(\boldsymbol{n}=\mathbf{3 2}) \\
\end{array}$ & $\begin{array}{l}\text { Control group } \\
(\boldsymbol{n}=\mathbf{3 7})\end{array}$ & $\mathbf{p}^{*}$ \\
& Median $\left(\mathbf{I Q}_{\mathbf{2 5}-75}\right)$ & Median $\left(\mathbf{I Q}_{\mathbf{2 5}-75}\right)$ & \\
\hline GPX activity U/L & $7.682(6548-8446)$ & $9.284(8440-10,720)$ & $\mathbf{0 . 0 0 2}$ \\
Selenium $\mu \mathrm{g} / \mathrm{L}$ & $45.6(37.3-56.2)$ & $57.8(46.0-66.0)$ & $\mathbf{0 . 0 0 4}$ \\
MDA nmol/mL & $3.5(3.1-3.9)$ & $3.2(2.4-4.0)$ & 0.514 \\
us-CRP mg/L & $6.3(0.9-17.7)$ & $1.8(0.8-1.8)$ & 0.124 \\
Glucose mg/dL & $85.5(81.0-92.0)$ & $85.0(77.0-95.0)$ & 0.813 \\
Insulin U/mL & $6.6(2.6-10.8)$ & $8.1(5.2-13.8)$ & 0.155 \\
HOMA-IR & $1.2(0.5-2.2)$ & $1.6(0.9-2.9)$ & 0.177 \\
AST U/L & $19.0(15.5-24.0)$ & $18.0(15.0-19.0)$ & 0.116 \\
ALT U/L & $10.0(8.0-14.0)$ & $12.0(9.0-17.0)$ & 0.108 \\
GGT U/L & $14.0(10.3-25.8)$ & $16.3(10.7-21.5)$ & 0.519 \\
\hline
\end{tabular}

Significance level of Mann-Whitney test

GPX Erythrocyte glutathione peroxidase, us-CRP Ultrasensitive protein $C$ reactive, MDA Malondialdehyde, HOMA-IR Homeostasis Model Assessment for Insulin Resistance, AST Aspartate transaminase, ALT Alanine aminotransferase, GGT Gamma-glutamyl transferase
The comparison of laboratory variables is shown in Table 3. Se median levels and GPX activity were significantly lower in patients compared to controls There was a higher percentage of high values of $\mathrm{C}$-reactive protein in the group of CVID patients compared to controls [8 (36.4\%) vs. 2 (11.1\%); $p=0.082$ ].

In the group of CVID patients, there was no difference between Se concentrations and GPX activity in those with and without chronic lung disease. However, those who had chronic diarrhea had lower Se plasma levels [35.0 (30.4-35.8) vs. 48.0(41.1-61.4); $p=0.003$ ] and GPX activity $[6379(6036-6717)$ vs. 7827 (70868756); $p=0.030$ ) compared to those who did not have this associated morbidity.

Regarding dietary intake, we observed that the CVID group had a lower intake of polyunsaturated fat $(p=$ $0.006)$ and a higher intake of zinc $(p=0.028)$ and retinol ( $p=0.026)$ than the control group. There was no statistically significant difference in Se intake (median) between CVID patients and controls [66.3 (56.7-79.3) vs. 66.2 (60.8-72.3); $p=0.682$ ] (data not shown). There was no association between Se intake and age $(p=0.197)$.

The lipid status biomarkers are shown in Table 4. Higher concentrations of oxidized LDL $(45.3 \mathrm{mg} / \mathrm{dL}$ vs. $33.3 \mathrm{mg} / \mathrm{dL} ; p=0.016)$ and lower concentrations of Apo A-1 $(98.5 \mathrm{mg} / \mathrm{dL})$ vs. $117.0 \mathrm{mg} / \mathrm{dL} ; p=0.008)$ were observed in the CVID group compared to the control.

There was no significant correlation between GPX activity and the variables studied in CVID patients. In turn, there was a significant and positive correlation between Se plasma levels and apolipoprotein A-1 concentrations in the CVID group (Fig. 1).

Se values less than $46 \mu \mathrm{g} / \mathrm{L}(\mathrm{OR}=3.590 ; 95 \% \mathrm{CI}$ 1.103 to $11.687 ; p=0.034$ ) and GPX activity below the 4 th quartile $(\mathrm{OR}=21.703 ; 95 \% \mathrm{CI} 2.534$ to $185.914 ; p=$ 0.005 ) were independently associated, after adjustment for age, overweight and dyslipidemia, with the CVID group (Table 5).

\section{Discussion}

The study showed significantly lower values of Se plasma levels and GPX activity in CVID patients compared to healthy controls. There was a significant and positive correlation between Se levels and Apo A-1 concentrations, a negative reactive acute-phase protein, and the main protein component of the HDL cholesterol fraction.

According to our knowledge, this study is a pioneer in assessing the association between Se concentrations and GPX activity with lipid status biomarkers in CVID patients. A recent paper evaluating 124 men with human immunodeficiency virus (HIV) infection described serum Se deficiency in $65.9 \%$ of individuals. There was a significant and negative correlation between the 
Table 4 Family cardiovascular risk and lipid status biomarkers of CVID patients and control group

\begin{tabular}{|c|c|c|c|}
\hline \multirow[t]{2}{*}{ Variables } & \multirow{2}{*}{$\begin{array}{l}\text { CVID Patients } \\
(n=32) \\
\text { Median }\left(1 Q_{25-75}\right)\end{array}$} & $\begin{array}{l}\text { Control group } \\
(n=37)\end{array}$ & \multirow[t]{2}{*}{$p^{*}$} \\
\hline & & Median $\left(\mathbf{I Q}_{25-75}\right)$ & \\
\hline Family CVR Yes & $13(40.6)$ & $16(43.2)$ & 0.826 \\
\hline \multicolumn{4}{|l|}{ Lipid status biomarkers } \\
\hline Total cholesterol mg/dL & $166.0(138.5-185.0)$ & $179.0(164.0-213.0)$ & 0.085 \\
\hline LDL-c mg/dL & 100.1 (86.0-116.6) & $108.8(84.2-139.0)$ & 0.237 \\
\hline Triglycerides mg/dL & $91.0(78.5-104.0)$ & $91.0(75.0-121.0)$ & 0.995 \\
\hline $\mathrm{HDL}-\mathrm{c} \mathrm{mg} / \mathrm{dL}$ & $43.0(34.5-52.5)$ & $48.0(37.0-56.0)$ & 0.210 \\
\hline NHDL-c mg/dL, \% & $118.0(104.0-138.0)$ & $135.0(108.0-161.0)$ & 0.226 \\
\hline VLDL-c mg/dL & $18.2(15.6-20.8)$ & $18.2(15.0-24.2)$ & 0.990 \\
\hline Remnant cholesterol mg/dL & $18.5(15.6-20.8)$ & $18.2(15.0-22.8)$ & 0.909 \\
\hline Oxidized LDL mg/dL & $45.3(26.8-65.7)$ & $33.3(23.7-42.2)$ & 0.016 \\
\hline Apo A-1 mg/dL & $98.5(81.5-112.5)$ & $117.0(92.0-130.0)$ & 0.008 \\
\hline Apo B mg/dL & $94.0(81.0-111.5)$ & $102.0(90.0-119.0)$ & 0.215 \\
\hline Apo B/ Apo A-1 & $0.9(0.7-1.1)$ & $0.8(0.6-1.0)$ & 0.238 \\
\hline Total cholesterol/HDL-c & $4.0(3.0-4.0)$ & $4.0(3.0-4.0)$ & 0.484 \\
\hline LDL-c/ Apo B & $1.0(0.9-1.2)$ & $1.0(0.9-1.2)$ & 0.976 \\
\hline LDL-C/ HDL-C & $2.0(2.0-3.0)$ & $2.0(2.0-3.0)$ & 0.442 \\
\hline TG/ HDL-C & $2.0(2.0-3.0)$ & $2.0(1.0-3.0)$ & 0.516 \\
\hline Apo A-1/ HDL-c & $2.3(1.9-2.5)$ & $2.3(1.2-2.6)$ & 0.392 \\
\hline
\end{tabular}

* Significance level Mann-Whitney test

CVR Cardiovascular risk, LDL-c Low-density lipoprotein, HDL-c High-density lipoprotein, NHDL-c Non-HDL cholesterol, VLDL-c Very low-density lipoprotein, TG Triglycerides, Apo A-1 Apolipoprotein A-1

concentrations of Se and pro-inflammatory cytokines (IL-1beta, IL-6, and TNF-alpha). The authors emphasized that Se deficiency has been associated with increased morbimortality and other adverse outcomes in HIV+ individuals [24].
A study recently published by our group in patients with ataxia-telangiectasia (inborn error of immunity and neurodegeneration) showed inadequate Se values in $40 \%$ of patients, with a significant association with oxidative stress biomarkers [25].

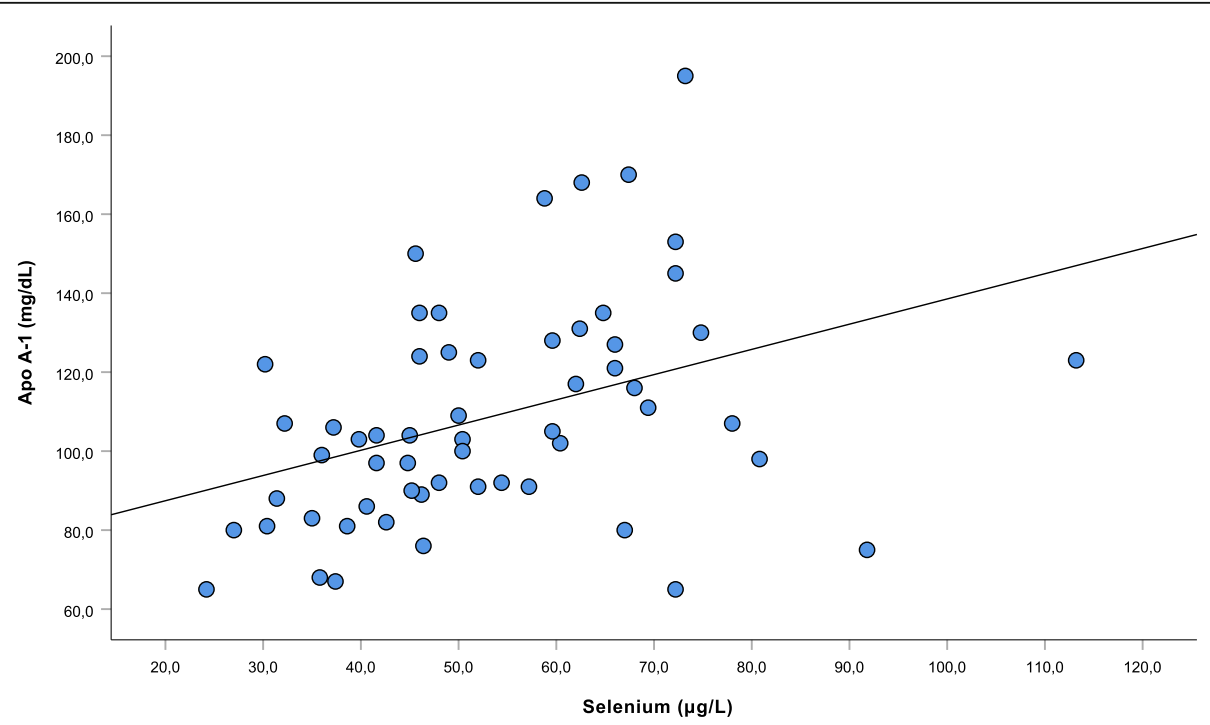

Fig. 1 Correlation of Se plasma levels with Apolipoprotein A-1 levels in CVID patients. Level of significance of Spearman's correlation. Se (ug/L) $x$ Apo A-1 (mg/dL) 
Table 5 Predictor variables for selenium and glutathione peroxidase values

\begin{tabular}{|c|c|c|c|c|c|}
\hline Model I & & $\beta$ & \multicolumn{2}{|c|}{ Confidence interval 95\% } & $P$ value \\
\hline Age & years & 0.981 & 0.939 & 1.026 & 0.404 \\
\hline Group & CVID & 3.590 & 1.103 & 11.687 & 0.034 \\
\hline Dyslipidemia & yes & 0.812 & 0.222 & 2.968 & 0.753 \\
\hline Nutritional status & overweight & 0.494 & 0.151 & 1.613 & 0.243 \\
\hline Model II & & $\beta$ & \multicolumn{2}{|c|}{ Confidence interval 95\% } & Valor $\mathrm{p}$ \\
\hline Age & years & 0.990 & 0.938 & 1.044 & 0.705 \\
\hline Group & CVID & 21.703 & 2.534 & 185.914 & 0.005 \\
\hline Dyslipidemia & yes & 2.993 & 0.501 & 17.881 & 0.229 \\
\hline Nutritional status & overweight & 0.427 & 0.103 & 1.761 & 0.239 \\
\hline
\end{tabular}

Model I: Dependent variable: Selenium levels $<46 \mu \mathrm{g} / \mathrm{L}$

Model II: Dependent variable: Glutathione peroxidase activity $<1^{\circ}$ Quartile $(<7384.5 \mathrm{U} / \mathrm{L})$

Inborn errors of immunity have different clinical characteristics, especially recurrent infections linked to incompetence in regulating different homeostatic processes, with an increased risk of the development of tumors and autoimmune diseases [26, 27]. Furthermore, in predominantly humoral deficiencies, patients are exposed to extracellular bacteria and have severe and recurrent sinopulmonary infections requiring hospitalization and frequent antibiotics use. Bacterial infections are associated with a reduction in serum selenium concentrations, and supplementation studies show favorable results [27].

Many bacteria can also synthesize selenocysteine, suggesting that selenoproteins may play a role in bacterial physiology. Simultaneously, the composition of the host's microbiota is also regulated by the diet Se. Therefore, pathogenic bacteria, microbiome, and cells of the host's immune system may be competing for a limited supply of Se, which is of even more significant concern in CVID patients [28-30].

A significant and direct correlation was observed between Se and Apo A-1 concentrations. The literature has shown that Apo A-1 and other HDL-c functionality markers are superior to HDL-c concentrations in predicting risk for cardiovascular disease [31].

Se suppresses the activation of pro-inflammatory pathways by chelating free radicals and blocking the nuclear transcription factor NF-kB activation. Changes in the composition and concentration of lipoproteins that occur in inflammation can alter these particles' function, making them pro-inflammatory. Thus, besides the quantitative alterations, significant changes are also observed in the composition of these lipoproteins, especially in the case of HDL-c that loses its major Apo A-1 protein component, which is replaced by an acute-phase protein, namely, serum amyloid A, which during inflammation, represents $90 \%$ of proteins found in HDL-c. Se deficiency can contribute to the disruption of inflammation, contributing to the generation of dysfunctional HDL-c, that is, a pro-inflammatory particle $[32,33]$.
A significant transition is expected in the microbiota of CVID patients characterized by reduced intraindividual bacterial diversity due to antibiotic use. Some studies suggest a link between immunodeficiency, systemic immune activation, and altered intestinal microbiota [34]. Thus, we can conclude that recurrent infections, inflammation, and changes in the microbiota contribute to high oxidative stress, insulin resistance, and consequent elevated risk of dyslipidemia [35].

CVID patients compared to healthy controls showed in the present study cardiovascular risk evidenced by: higher percentage of high us-CRP, lower values of plasma Se and GPX activity, higher concentrations of LDLox and lower levels of Apo A-1.

Specific LDLox receptors called LOX-1 and SR-PSOX have been isolated. The expression of LOX-1 is found in endothelial cells, smooth muscle cells, and macrophages, while SR-PSOX is expressed in macrophages. LDLox can be produced due to the increased production of reactive species by the mitochondria during oxidative stress and inflammation [36]. Such findings reinforce the atherosclerotic risk of CVID patients.

Publications assessing CVD risk and its interface with Se are scarce in the literature. In a study of 20 CVID patients and 16 healthy controls, Aukrust et al. (1997) [37] reported high concentrations of malondialdehyde (lipid peroxidation biomarker) and reduced homocysteine in the group of patients, suggesting the existence of oxidative stress. Future studies are required to assess the effect of selenium supplementation on CVD risk in CVID patients.

In conclusion, this study showed an higher percentage of high us-CRP, lower values of plasma selenium and GPX activity, higher concentrations of LDLox and lower levels of Apo A-1 in CVID patients in comparison to controls, suggesting oxidative stress and cardiovascular risk. These data point to the importance of assessing the Se status and cardiovascular risk in these patients. 


\section{Abbreviations}

ALT: Alanine transaminase; Apo B: Apolipoprotein B; Apo A1: Apolipoprotein A-1; AST: Aspartate aminotransferase; BMl: Body mass index; CVDs: Cardiovascular diseases; CVID: Common Variable Immunodeficiency; CVR: Cardiovascular risk; FAPESP: São Paulo Research Foundation; GGT: Gamma-glutamyl transpeptidase; GPX: Glutathione peroxidase; H/ A: Height for age; HDL-c: High-density lipoprotein cholesterol; HIV: Human immunodeficiency virus; HOMA-IR: Homeostasis Model Assessment of Insulin Resistance; IEl: Inborn error of immunity; LDL-c: Low-density lipoprotein cholesterol; LDLox: Oxidized LDL; MDA: Malondialdehyde; NCEP: National Cholesterol Education Program; NFkB: Nuclear transcription fator B; NHDLc: Non-HDLc; Se: Selenium; SNP: Single nucleotide polymorphism; TC: Total cholesterol; TG: Triglycerides; us-CRP: Ultra-sensitive C-reactive protein; VLDLc: Very-low-density lipoprotein cholesterol; WHO: World Health Organization

\section{Acknowledgements}

This paper is dedicated to the memory of Beatriz Tavares Costa-Carvalho.

\section{Authors' contributions}

IGAA $\rightarrow$ collected, analyzed and interpreted data from CVID patients and the control group and was a major contributor in writing the manuscript. FISS $\rightarrow$ analyzed and interpreted data from CVID patients and the control group and contributed to the correction of the manuscript writing. FLAF $\rightarrow$ performed the analysis of laboratory tests and contributed to the correction of the manuscript writing. CSAL $\rightarrow$ analyzed and interpreted data from CVID patients and the control group and contributed to the correction of the manuscript writing. ROSS $\rightarrow$ analyzed and interpreted data from CVID patients and the control group and was a major contributor in writing the manuscript. All authors read and approved the final manuscript.

\section{Funding}

The study was financed by The São Paulo Research Foundation - FAPESP $n^{\circ}$ 2015/13308-9. The Foundation FAPESP did not influence in the design of the study and collection, analysis, and interpretation of data or the writing of the manuscript.

\section{Availability of data and materials}

The datasets used and/or analysed during the current study are available from the corresponding author on reasonable request.

\section{Declarations}

\section{Ethics approval and consent to participate}

The study was approved by The Research Ethics Committee from the Federal University of São Paulo (CEP/UNIFESP - 972.812 11/03/2015) and signed informed consents were obtained from all participants (or a responsible guardian in the case of children). Research was performed in accordance with the Declaration of Helsinki.

\section{Consent for publication}

Not applicable.

\section{Competing interests}

The authors declare that they have no competing interests. This work was supported by the Fundação de Amparo à Pesquisa do Estado de São Paulo FAPESP $n^{\circ}$ 2015/13308-9.

\section{Author details}

'Department of Pediatrics, Universidade Federal de São Paulo - Escola Paulista de Medicina, Rua Dr. Diogo de Faria, 671, São Paulo, SP CEP 04037002, Brazil. 'Universidade Federal de São Paulo - Campus Diadema, Diadema, Brazil. ${ }^{3}$ Department of Pediatrics, Faculdade de Medicina do ABC/ Centro Universitário FMABC, Santo André, Brazil. ${ }^{4}$ Department of Pediatrics, Universidade Federal de São Paulo - Escola Paulista de Medicina, São Paulo, Brazil.
Received: 9 January 2021 Accepted: 4 May 2021

Published online: 13 May 2021

\section{References}

1. Benstoem C, Goetzenich A, Kraemer S, Borosch S, Manzanares W, Hardy G, et al. Selenium and its supplementation in cardiovascular disease--what do we know? Nutrients. 2015;7(5):3094-118. https://doi.org/10.3390/nu7053094.

2. Berthold HK, Michalke B, Krone W, Guallar E, Gouni-Berthold I. Influence of serum selenium concentrations on hypertension: the lipid analytic cologne cross-sectional study. J Hypertens. 2012;30(7):1328-35. https://doi.org/10.1 097/HJH.0b013e32835414df.

3. Köhrle J. Selenium in Endocrinology-Selenoprotein-Related Diseases, Population Studies, and Epidemiological Evidence. Endocrinology. 2021; 162(2):bqaa228. https://doi.org/10.1210/endocr/bqaa228.

4. Lopes Junior $E$, Leite HP, Konstantyner T. Selenium and selenoproteins: from endothelial cytoprotection to clinical outcomes. Transl Res. 2019;208:85-104. https://doi.org/10.1016/j.trsl.2019.01.004.

5. Hamanishi T, Furuta H, Kato H, Doi A, Tamai M, Shimomura H, et al. Functional variants in the glutathione peroxidase-1 (GPX-1) gene are associated with increased intima-media thickness of carotid arteries and risk of macrovascular diseases in Japanese type 2 diabetic patients. Diabetes. 2004;53(9):2455-60. https://doi.org/10.2337/diabetes.53.9.2455.

6. Kuzuya M, Ando F, Iguchi A, Shimokata H. Glutathione peroxidase 1 Pro198Leu variant contributes to the metabolic syndrome in men in a large Japanese cohort. Am J Clin Nutr. 2008;87(6):1939-44. https://doi.org/10.1 093/ajcn/87.6.1939.

7. Cammisotto V, Nocella C, Bartimoccia S, Sanguigni V, Francomano D, Sciarretta S, et al. The role of antioxidants supplementation in clinical practice: focus on cardiovascular risk factors. Antioxidants (Basel). 2021;10(2): 146. https://doi.org/10.3390/antiox10020146.

8. Gupta S, Pattanaik D, Krishnaswamy G. Common variable immune deficiency and associated complications. Chest. 2019;156(3):579-93. https:// doi.org/10.1016/j.chest.2019.05.009.

9. Schwimmer D, Glover S. Primary immunodeficiency and the gut. Gastroenterol Clin N Am. 2019;48(2):199-220. https://doi.org/10.1016/j.gtc.2 019.02.004.

10. Basaranoglu ST, Cekic S, Kirhan E, Dirican M, Kilic SS. Oxidative stress in common variable immunodeficiency. Eur J Inflammation. 2021;19:1-8. https://doi.org/10.1177/20587392211002411.

11. Vieira DG, Costa-Carvalho BT, Hix S, da Silva R, Correia MS, Sarni RO. Higher cardiovascular risk in common variable immunodeficiency and X-linked Agammaglobulinaemia patients. Ann Nutr Metab. 2015;66(4):237-41. https://doi.org/10.1159/000435818.

12. Ameratunga $R$, Brewerton $M$, Slade C, Jordan A, Gillis D, Steele R, et al. Comparison of diagnostic criteria for common variable immunodeficiency disorder. Front Immunol. 2014;5:415. https://doi.org/10.3389/fimmu.2014.00415.

13. World Health Organization. Physical status: the use and interpretation of anthropometry: report of a WHO Expert Committee, vol. 854. Geneva: WHO; 1995. p. 1-452. (Technical Report Series)

14. De Onis M, Onyango AW, Borghi E, Siyam A, Nishida C, Siekmann J. Development of a WHO growth reference for school-aged children and adolescents. Bull World Health Organ. 2007;85(9):660-7. https://doi.org/10.24 71/blt.07.043497.

15. Freedman DS, Serdula MK, Srinivasan SR, Berenson GS. Relation of circumferences and skinfold thicknesses to lipid and insulin concentrations in children and adolescents: the Bogalusa heart study. Am J Clin Nutr. 1999; 69(2):308-17. https://doi.org/10.1093/ajcn/69.2.308.

16. Cavalcante AAM, Priore SE, Franceschini SCC. Food consumption studies: general methodological aspects and its use in the evaluation of children and adolescents aged. Rev Bras Saude Mater Infant. 2004;4(3):229-40. https://doi.org/10.1590/S1519-38292004000300002.

17. Bueno AL, Czepielewski MA. The 24 hours recall for the assessment of dietary calcium, phosphorus and vitamin D intakes in stunted children and adolescents. Rev Nutr Camp. 2010;23(1):65-73. https://doi.org/10.1590/S141 5-52732010000100008.

18. Ferreira $K S$, Gomes $J C$, Bellato $C R$, Jordão $C P$. Concentrações de selênio em alimentos consumidos no Brasil. Rev Panam de Salud Pública. 2002;11(3): 172-7.

19. Satoh K. Serum lipid peroxide in cerebrovascular disorders determined by a new colorimetric method. Clin Chim Acta. 1978;90(1):37-43. https://doi. org/10.1016/0009-8981(78)90081-5. 
20. Friedewald WT, Levy RI, Fredrickson DS. Estimation of the concentration of low-density lipoprotein cholesterol in plasma, without use of the preparative ultracentrifuge. Clin Chem. 1972;18(6):499-502. https://doi.org/1 0.1093/clinchem/18.6.499.

21. Daniels SR. Greer FR; committee on nutrition. Lipid screening and cardiovascular health in childhood. Pediatrics. 2008;122(1):198-208. https:// doi.org/10.1542/peds.2008-1349.

22. National Cholesterol Education Program (NCEP) Expert Panel on Detection. Evaluation, and treatment of high blood cholesterol in adults (adult treatment panel III): third report of the National Cholesterol Education Program (NCEP) expert panel on detection, evaluation and treatment of high blood cholesterol in adults (adult treatment panel III) final report. Circulation. 2002;106(25):3143-421.

23. Berenson GS, Srinivasan SR, Bao W, Newman WP 3rd, Tracy RE, Wattigney WA. Association between multiple cardiovascular risk factors and atherosclerosis in children and young adults. The Bogalusa heart study. N Engl J Med. 1998; 338(23):1650-6. https://doi.org/10.1056/NEJM199806043382302.

24. Osuna-Padilla IA, Briceño O, Aguilar-Vargas A, Rodríguez-Moguel NC, Villazon-De la Rosa A, Pinto-Cardoso S, et al. Zinc and selenium indicators and their relation to immunologic and metabolic parameters in male patients with human immunodeficiency virus. Nutrition. 2019;70:110585. https://doi.org/10.1016/j.nut.2019.110585.

25. Andrade IGA, Suano-Souza FI, Fonseca FLA, Lago CSA, Sarni ROS. Selenium levels and glutathione peroxidase activity in patients with ataxia-telangiectasia: association with oxidative stress and lipid status biomarkers. Orphanet J Rare Dis. 2021:16(1):83. https://doi.org/10.1186/s13023-021-01732-5.

26. Bousfiha A, Jeddane L, Picard C, Ailal F, Bobby Gaspar H, Al-Herz W, et al. The 2017 IUIS phenotypic classification for primary immunodeficiencies. J Clin Immunol. 2018;38(1):129-43. https://doi.org/10.1007/s10875-017-0465-8.

27. Steinbrenner H, Al-Quraishy S, Dkhil MA, Wunderlich F, Sies H. Dietary selenium in adjuvant therapy of viral and bacterial infections. Adv Nutr. 2015;6(1):73-82. https://doi.org/10.3945/an.114.007575.

28. Cambray-Gutiérrez JC, Fernández-Muñoz MJ, Del Rivero-Hernández LG, López-Pérez P, Chávez-García AA, Segura-Méndez NH. Structural and functional heart diseases in adult patients with common variable immunodeficiency. Rev Alerg Mex. 2015;62(2):91-7. https://doi.org/10.29262/ ram.v62i2.69.

29. Sumner SE, Markley RL, Kirimanjeswara GS. Role of Selenoproteins in bacterial pathogenesis. Biol Trace Elem Res. 2019;192(1):69-82. https://doi. org/10.1007/s12011-019-01877-2.

30. Steinbrenner $\mathrm{H}$, Speckmann B, Sies H. Toward understanding success and failures in the use of selenium for cancer prevention. Antioxid Redox Signal. 2013;19(2):181-91. https://doi.org/10.1089/ars.2013.5246.

31. Asztalos BF, Horvath KV, Schaefer EJ. High-density lipoprotein particles, cellcholesterol efflux, and coronary heart disease risk. Arterioscler Thromb Vasc Biol. 2018;38(9):2007-15. https://doi.org/10.1161/ATVBAHA.118.311117.

32. Ju W, Ji M, Li X, Li Z, Wu G, Fu X, et al. Relationship between higher serum selenium level and adverse blood lipid profile. Clin Nutr. 2018;37(5):1512-7. https://doi.org/10.1016/j.Inu.2017.08.025.

33. Riwanto $M$, Rohrer $L$, von Eckardstein $A$, Landmesser U. Dysfunctional $H D L$ : from structure-function-relationships to biomarkers. Handb Exp Pharmacol. 2015;224:337-66. https://doi.org/10.1007/978-3-319-09665-0_10.

34. Kim SH, Johnson VJ, Shin TY, Sharma RP. Selenium attenuates lipopolysaccharide-induced oxidative stress responses through modulation of p38 MAPK and NF-kappaB signaling pathways. Exp Biol Med (Maywood). 2004;229(2):203-13. https://doi.org/10.1177/153537020422900209.

35. Jørgensen SF, Trøseid M, Kummen M, Anmarkrud JA, Michelsen AE, Osnes $L T$, et al. Altered gut microbiota profile in common variable immunodeficiency associates with levels of lipopolysaccharide and markers of systemic immune activation. Mucosal Immunol. 2016;9(6):1455-65. https://doi.org/10.1038/mi.2016.18.

36. Frostegård J. Immunity, atherosclerosis and cardiovascular disease. BMC Med. 2013;11:117. https://doi.org/10.1186/1741-7015-11-117.

37. Aukrust P, Berge RK, Müller F, Ueland PM, Svardal AM, Frøland SS. Elevated plasma levels of reduced homocysteine in common variable immunodeficiency--a marker of enhanced oxidative stress. Eur J Clin Investig. 1997;27(9):723-30. https://doi.org/10.1046/j.1365-2362.1997.18807328.x.

\section{Publisher's Note}

Springer Nature remains neutral with regard to jurisdictional claims in published maps and institutional affiliations.

Ready to submit your research? Choose BMC and benefit from:

- fast, convenient online submission

- thorough peer review by experienced researchers in your field

- rapid publication on acceptance

- support for research data, including large and complex data types

- gold Open Access which fosters wider collaboration and increased citations

- maximum visibility for your research: over $100 \mathrm{M}$ website views per year

At BMC, research is always in progress.

Learn more biomedcentral.com/submissions 